\title{
High-fat diets promote colon orthotopic transplantation tumor metastasis in BALB/c mice
}

\author{
LIJUAN XIU $^{1 *}$, ZHIHUI YANG ${ }^{2 *}$, YING ZHAO $^{1 *}$, XUAN LIU $^{1 *}$, \\ JIANPENG JIAO ${ }^{1}$, MIN YE ${ }^{1}$, DAZHI SUN ${ }^{1}$ and PINKANG WEI \\ ${ }^{1}$ Department of Traditional Chinese Medicine, Shanghai Changzheng Hospital, Shanghai 200003; ${ }^{2}$ Department of Pathology, \\ 81st Hospital Affiliated to Nanjing University of Chinese Medicine, Nanjing, Jiangsu 210002, P.R. China
}

Received October 9, 2015; Accepted February 5, 2018

DOI: $10.3892 / \mathrm{ol} .2018 .9742$

\begin{abstract}
High-fat diets (HFDs) are a risk factor for colorectal cancer. The present study investigated whether HFDs increase colon cancer metastasis in BALB/c mice. A total of $40 \mathrm{BALB} / \mathrm{c}$ mice were divided into four groups, including the tumor, tumor-HFD, HFD and control groups. After 3 weeks, the tumor weights and metastases were observed. The serum levels of triglyceride, total cholesterol, lapin, interleukin-6 (IL-6) and tumor necrosis factor were analyzed using ELISA. The CD34, vascular endothelial growth factor (VEGF) and angiotensin 2 (ANG2) protein and mRNA levels in tumor tissues were analyzed with immunohistochemistry and reverse transcription-polymerase chain reaction. The metastasis frequency increased in the tumor-HFD group. However, there was no difference in the mean tumor weight between the tumor-HFD and tumor groups. The serum cholesterol levels were increased in the tumor-HFD and HFD groups compared with the control group. The levels of serum IL- 6 and tumor necrosis factor- $\alpha$ were increased in the tumor-HFD group compared with other groups. The CD34 protein level, and VEGF protein and mRNA levels were increased in the tumor-HFD group compared with the tumor group. No difference was identified between the ANG2 protein and mRNA levels in of the two groups. It was concluded that HFD increased the serum level of cholesterol and cytokines, and potentially induced tumor angiogenesis, promoting transplanted orthotopic colon tumor metastasis in BALB/c mice.
\end{abstract}

Correspondence to: Professor Pinkang Wei or Dr Dazhi Sun, Department of Traditional Chinese Medicine, Shanghai Changzheng Hospital, 415 Fengyang Road, Shanghai 200003, P.R. China

E-mail: czzyk73@163.com

E-mail: sun-dazhi@126.com

*Contributed equally

Key words: colon cancer, high-fat diet, inflammation, angiogenesis

\section{Introduction}

Colorectal cancer (CRC) is the second-leading cause of cancer-associated mortality worldwide (1). Patients are frequently initially diagnosed at an advanced stage of disease, when distant metastasis is likely to be present. The mechanisms of metastasis in CRC remain incompletely characterized.

High-fat diets (HFDs) are a risk factor for numerous conditions, including obesity $(2)$, insulin resistance $(3,4)$, non-alcoholic fatty liver disease (5), hypertension and atherosclerosis (6). HFD, particularly when including animal fat, is also a risk factor for CRC (7-9). An abnormal lipid profile contributes to the development of CRC. Notarnicola et al (10) observed 84 patients with CRC and reported that the levels of total cholesterol (TC), low-density lipoprotein (LDL)-C and LDL-C/high-density lipoprotein- $\mathrm{C}$ were all increased in patients with metastasis compared with patients without metastasis. However, the mechanism of abnormal lipid metabolism in affecting CRC progress remains unclear.

Angiogenesis is an important contributing factor to tumor metastasis. CD34 is the major marker for tumor angiogenesis, invasiveness and metastasis. Tumor angiogenesis consists of numerous steps, during which vascular endothelial growth factor (VEGF) and angiotensin (ANG)2 are particularly important $(11,12)$. VEGF promotes the growth and migration of vascular endothelial cells, induces tumor angiogenesis and promotes the permeability of microvessels and venules $(13,14)$. ANG2 can facilitate angiogenesis by disrupting endothelial cell-pericyte interactions in primary tumors and enhancing the permeability of vessels (13). ANG2 promotes the VEGF-induced migration and proliferation of ECs, and facilitates the growth of new blood vessels in the presence of growth factors (15). Angiogenesis can be induced by chronic inflammation (16), which may result from HFD (17). Thus, HFD may contribute to the progress of CRC by promoting angiogenesis.

The aim of the present study was to observe the effect of HFD on the metastasis and angiogenesis of colon orthotopic transplantation tumors in BABL/c mice, and to identify the mechanism of the effect of HFD on metastasis. It was demonstrated that HFD increased the level of cytokines, and induced tumor angiogenesis, to promote colon orthotopic transplantation tumor metastasis in $\mathrm{BALB} / \mathrm{c}$ mice. 


\section{Materials and methods}

Materials. ELISA kits for interleukin-6 (IL-6; cat. no. 550950), tumor necrosis factor (TNF)- $\alpha$ (cat. no. 560478) and mouse lipoprotein were purchased from BD Biosciences (Franklin Lakes, NJ, USA). Anti-vascular endothelial growth factor (VEGF) antibody (EP1176Y), anti-CD34 antibody (EP373Y) and anti-angiotensin 2 (ANG2) antibody [EPR2891(2)] (all from Abcam, Cambridge, UK; all rabbit monoclonal), and kits for the determination of triglyceride (TG; cat. no. 006304) and total cholesterol (TC; cat. no. 006301) were purchased from Beijing BHKT Clinical Reagent Co., Ltd. (Beijing, China).

Animals. A total of 41 six-week-old BALB/c mice (specific pathogen-free grade; half male, half female; body weights $\sim 20 \pm 2 \mathrm{~g}$ ) were purchased from and housed at the Shanghai Laboratory Animals Center (SLAC) of the Chinese Academy of Sciences (Shanghai, China). The housing conditions were as follows: $24 \pm 2^{\circ} \mathrm{C}, 50 \pm 10 \%$ relative humidity, and a 12-h light/dark cycle. The animals had ad libitum access to food and water. The housing facility and all animal experiments were conducted in accordance with the guidelines established by the Beijing Administration Office of Laboratory Animals; the study protocol was approved by the Institutional Animal Care and Use Committee of SLAC.

Cell line. CT26 mouse colon cancer cells were provided as a gift by SLAC. The cells were incubated at $37^{\circ} \mathrm{C}$. They were maintained in Dulbecco's modified Eagle's medium containing $100 \mathrm{ml} / \mathrm{l}$ fetal bovine serum (Gibco; Thermo Fisher Scientific, Inc., Waltham, MA, USA) with $100,000 \mathrm{U} / 1$ of penicillin and $100 \mathrm{mg} / \mathrm{l}$ of streptomycin in a humidified atmosphere of $5 \% \mathrm{CO}_{2}$.

Colon cancer orthograft model. CT26 cells $\left(5 \times 10^{6}\right.$ cells suspended in $0.2 \mathrm{ml}$ Matrigel) were injected into the right axillary subcutaneous region of a BALB/c mouse. When the tumor grew to $\sim 1 \mathrm{~cm}^{3}$, the mouse was sacrificed and the tumor was excised. The tumor lump was sliced into $1 \mathrm{~mm}^{3}$ pieces to make a colon cancer orthograft model.

The remaining $\mathrm{BALB} / \mathrm{c}$ mice were divided into the following four groups: Tumor, tumor-HFD, HFD and control, with 10 mice in each group. The mice in the tumor-HFD and HFD groups were fed with HFD as previously described (18) whereas the other two groups were fed with a control diet. The HFD contained $92 \mathrm{~g} / \mathrm{kg}$ protein, $203 \mathrm{~g} / \mathrm{kg}$ fat and $128 \mathrm{~g} / \mathrm{kg}$ carbohydrate, while the control diet contained $78 \mathrm{~g} / \mathrm{kg}$ protein, $22 \mathrm{~g} / \mathrm{kg}$ fat and $320 \mathrm{~g} / \mathrm{kg}$ carbohydrate.

At 4 weeks, the mice were fasted for $12 \mathrm{~h}$ prior to surgery. The mice were anesthetized by injection with $4.5 \%$ chloral hydrate into the abdominal cavity. Subsequent to disinfection, they were cut along the right midline to expose the colon, and the muscular layer of the colon was opened with $1 \mathrm{ml}$ sterile needles. A piece of tumor was adhered to the cecum incision with medical OB biological glue in mice from the tumor-HFD and tumor groups, whereas mice in the HFD and control groups were treated with OB glue alone. The abdomen was closed. From the next day, the mice were fed with their previous diet continuously for 3 weeks.
Measurement of body and tumor weights. The body weights of mice were measured once a week with an electronic weighting scale. The tumor weights were measured by an electronic microbalance, following the sacrifice of mice and the excision of the tumors.

Quantification of metastasis. Metastasis was scored at five levels: 1 , no metastasis; 2 , one incidence of visceral metastasis; 3, 2 incidences of visceral metastases; 4, 3 incidences of visceral metastases and 5,>4 incidences of visceral metastases.

Tissue preparation. All mice were sacrificed by the cervical dislocation method. Blood was sampled from the retro-orbital plexus. Blood serum was extracted by centrifugation $\left(15,970 \mathrm{xg}\right.$ at $4^{\circ} \mathrm{C}$ for $\left.5 \mathrm{~min}\right)$ and stored at $-20^{\circ} \mathrm{C}$ until analysis. The lungs, liver, spleen, pancreas, greater omentum and distal rectum were stored in Eppendorf tubes with formalin at room temperature. Colon tumor tissues were stored at $-80^{\circ} \mathrm{C}$.

Immunohistochemistry. Paraffin-embedded tissues were sectioned, deparaffinized, and rehydrated, and then washed in PBS ( $3 \times 3 \mathrm{~min})$. Antigen retrieval was performed in the microwave for $20 \mathrm{~min}$ in citrate buffer (2102-100; pH 6.0, $0.01 \mathrm{ml} / \mathrm{l}$; BioVision, Inc., Milpitas, CA, USA); sections were left at room temperature to cool, washed in PBS 3 times for $3 \mathrm{~min}$, treated with $0.3 \% \mathrm{H}_{2} \mathrm{O}_{2}$ at room temperature for endogenous peroxidase ablation (20 min) and washed in PBS 3 times for $3 \mathrm{~min}$ again. The sections were incubated with antibodies against $\mathrm{CD} 34$, VEGF and ANG2 (1:100) for $2 \mathrm{~h}$ at $37^{\circ} \mathrm{C}$. Subsequent to washing, the sections were incubated with goat anti-rabbit IgG, which was horseradish peroxidase-conjugated (1:300; A0208; Beyotime Institute of Biotechnology, Shanghai, China) at $37^{\circ} \mathrm{C}$ for $30 \mathrm{~min}$. Subsequent to further washing, the sections were reacted with 3,3-diaminobenzidine, left at room temperature without light for $10 \mathrm{~min}$, and then counterstained with hematoxylin, dehydrated, cleared and mounted with neutral gums.

The positive proportion of immunohistochemical staining and the optical density (OD) were measured by an IMS Cell Image Analysis system (Shanghai ShenTeng Information Technology Co., Ltd., Shanghai, China). Each section was analyzed at least in three fields of view. The immunohistochemistry index was calculated as the positive proportion $\mathrm{x} O D$.

Reverse transcription-polymerase chain reaction (RT-PCR). Tumor tissues were treated with TRIzol (Thermo Fisher Scientific, Inc.), chloroform and isopropyl alcohol to extract RNA. Following the reverse transcription of RNA to cDNA (Moloney Murine Leukemia Virus; $200 \mathrm{U} / \mathrm{ml}$; Invitrogen; Thermo Fisher Scientific, Inc.), primers were added for amplification with 40 cycles of $95^{\circ} \mathrm{C}$ for $30 \mathrm{sec}$ and $60^{\circ} \mathrm{C}$ for $30 \mathrm{sec}$. The primers were synthesized by Shanghai Ying jun Biological Technology Co., Ltd. (Shanghai, China; Table I). The Fluorescence quantitative PCR kit (Takara Biotechnology Co., Ltd., Dalian, China) was used according to the manufacturer's protocols. The products were subjected to a biological electrophoresis image analysis system for software-based PCR densitometry (FR-2000; Shanghai Furi Science \& Technology Co., Ltd., Shanghai, China). GAPDH was used as a reference gene. 
Table I. Primer sequences.

Gene name

Primer sequence (5'-3')

Product length, bp

Mouse GAPDH

123

Forward

AGGTCGGTGTGAACGGATTTG

Reverse

TGTAGACCATGTAGTTGAGGTCA

Mouse angiotensin 2

Forward

CCTCGACTACGACGACTCAGT

Reverse

TCTGCACCACATTCTGTTGGA

146

Mouse vascular endothelial growth factor

Forward

Reverse

AGCTACTGCCGTCCAATT

TCCAGGGCTTCATCGTTA

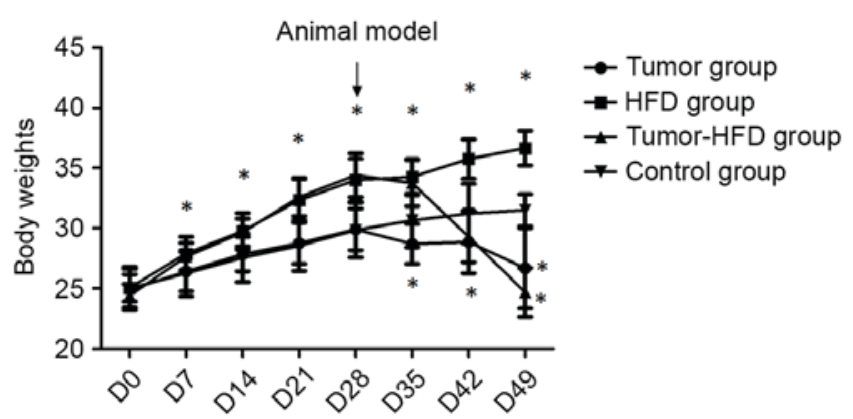

Figure 1. HFD decreased the body weight of colon cancer model mice. Results are expressed as the mean \pm standard deviation $(n=10) .{ }^{*} \mathrm{P}<0.05$ compared with the control group. HFD, high fat diet.

ELISA assays. Serum IL-6 (cat. no. 550950), TNF- $\alpha$ (cat. no. 560478), TG (cat. no. 006304), TC (cat. no. 006301) and lipoprotein a (cat. no. 006340) were examined by using Quantikine ELISA kits (BD Biosciences Company, USA) according to the manufacturer's protocol. Optical density was measured in an ELISA reader at $450 \mathrm{~nm}$ following a 15 -min incubation at room temperature.

Data analysis. The measurement data are expressed as the mean \pm standard deviation. Statistical analysis was performed using SPSS 21.0 (IBM Corp., Armonk, NY,USA). Comparisons between groups were tested by one-way analysis of variance followed by a least significant difference test. Differences in metastasis were analyzed by a Wilcoxon Rank-Sum test. Correlation analysis was performed by Pearson correlation coefficient. $\mathrm{P}<0.05$ was considered to indicate a statistically significant difference.

\section{Results}

Normal mouse body weight, but not orthotopic tumor-transplanted mouse body weight, increases following $H F D$. The body weights of the mice were measured twice a week. There was no difference between the mean body weights of the four groups before the experiment $(\mathrm{P}>0.05)$. One week later, the body weights of mice in the HFD group had significantly increased compared with the control group $(\mathrm{P}<0.05)$, whereas the body weights of mice decreased following colon orthotopic transplantation in the tumor-HFD and tumor groups. At the end of the experiment, the mean weight of the mice was higher in the HFD group than in the tumor-HFD group or control group $(\mathrm{P}<0.05)$, and was lower in the tumor and tumor-HFD groups than in the control group $(\mathrm{P}<0.05)$. The body weights of the mice in the tumor-HFD group were the lowest among the four groups (Fig. 1).

Metastasis severity is increased by HFD in mice transplanted with orthotopic tumors. The mean tumor weight was detected when the mice were sacrificed at 3 weeks after the colon cancer orthotopic transplantation surgery. The tumor weight was greater in the tumor-HFD group $(1.57 \pm 0.54 \mathrm{~g})$ than in the tumor group $(1.37 \pm 0.40 \mathrm{~g})$, but there was no significant difference between these two groups ( $\mathrm{P}=0.368$; Fig. 2A).

A total of 2 out of 10 mice died in the tumor-HFD group due to intestinal obstruction diagnosed by autopsy, while there was no mortality in the tumor group. The metastases in the lung, liver, spleen, pancreas, rectum and greater omentum were observed by immunohistochemistry. The metastases in the tumor group included two cases at level 1, five cases at level 2, two cases at level 3 and 1 case at level 4, whereas there were two cases at level 2 , two cases at level 3 , four cases at level 4 and 2 cases at level 5 in the tumor-HFD group. The severity of metastasis was greater in the tumor-HFD group than in the tumor group ( $\mathrm{P}<0.05$; Fig. $2 \mathrm{~B})$.

Serum cholesterol level is increased in mice transplanted with orthotopic tumors following HFD. ELISA was applied to determine whether HFD increased the serum cholesterol level. The serum cholesterol levels in the HFD and tumor-HFD groups were $5.10 \pm 0.84$ and $5.51 \pm 1.93 \mathrm{mmol} / 1$, respectively, which were higher than in the control group $(3.29 \pm 0.48 \mathrm{mmol} / \mathrm{l} ; \mathrm{P}<0.05)$. No difference was observed in serum cholesterol levels between the tumor group $(3.36 \pm 1.17 \mathrm{mmol} / \mathrm{l})$ and the control group $(\mathrm{P}>0.05)$. No difference was observed in serum $\mathrm{TG}$ or lipoprotein levels among the four groups ( $\mathrm{P}>0.05$; Fig. 3 ).

Serum levels of IL- 6 and TNF- $\alpha$ increase in mice transplanted with orthotopic tumors following HFD. The results of ELISA revealed that the serum levels of IL- 6 and TNF- $\alpha$, two cytokines associated with inflammation, increased markedly (118.57 \pm 68.07 and $18.94 \pm 5.39 \mathrm{pg} / \mathrm{ml}$, respectively) in the 

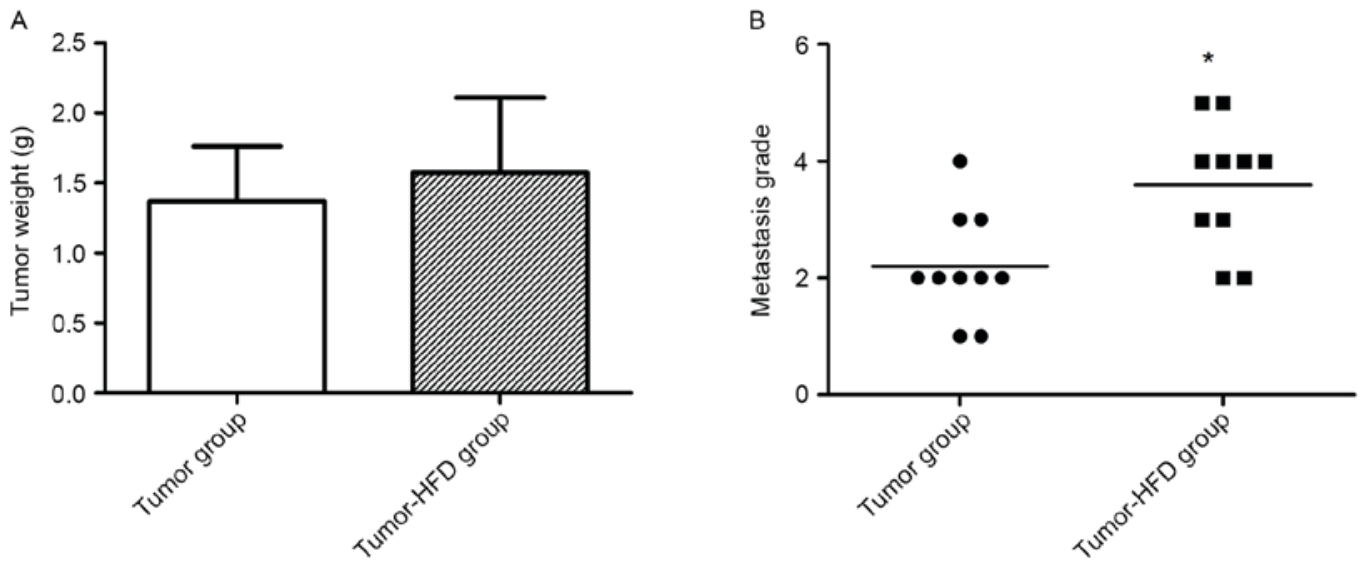

Figure 2. HFD promotes the metastasis of colon cancer model mice. (A) Tumor weight of the tumor-HFD group and tumor group at the end of the experiment. (B) Metastasis grade of the tumor-HFD group and tumor group at the end of the experiment, and the severity of metastasis was increased in the tumor-HFD group. ${ }^{*} \mathrm{P}<0.05$ vs. the tumor group. HFD, high fat diet.
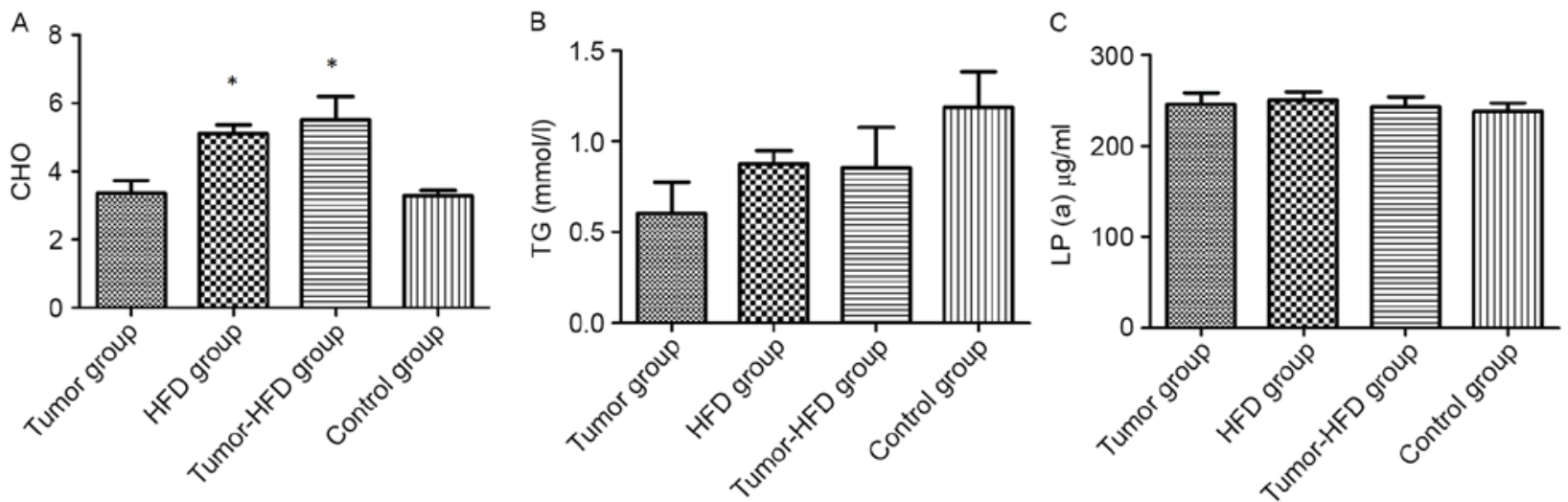

Figure 3. Serum levels of (A) CHO, (B) TG and (C) LP- $\alpha$. Results are expressed as the mean \pm standard deviation ( $\mathrm{n}=10$ ). ${ }^{*} \mathrm{P}<0.05$ compared with the control group. CHO, cholesterol; TG, triglycerides; LP, lipoprotein; HFD, high fat diet.

tumor-HFD group compared with the other groups $(\mathrm{P}<0.05$; Fig. 4). Although the serum levels of IL-6 and TNF- $\alpha$ in the tumor group $(64.06 \pm 33.56,10.69 \pm 6.74 \mathrm{pg} / \mathrm{ml})$ were higher than those in the control group $(29.79 \pm 14.78,6.19 \pm 3.51 \mathrm{pg} / \mathrm{ml})$, the differences were not statistically significant $(\mathrm{P}>0.05)$. The serum levels of IL-6 and TNF- $\alpha$ in the HFD group were similar to those in the control group $(\mathrm{P}>0.05)$.

Expression of CD34 protein, and VEGF and ANG2 protein and $\mathrm{mRNA}$ levels in colon cancer tissue, are increased following HFD. The results of IHC staining for CD34, a glycoprotein expressed on endothelial cells and platelets, revealed that the expression of CD34 was higher in the tumor-HFD group than in the tumor group (Fig. 5A and B). Similarly, the protein expression of VEGF, a key cytokine in tumor angiogenesis, was higher in the tumor-HFD group than in the tumor group $(1.77 \pm 0.83$ and $10.67 \pm 3.00)$; the differences were all statistically significant $(\mathrm{P}<0.05)$. The results of IHC staining for ANG2, another cytokine implicated in tumor angiogenesis, were $13.33 \pm 4.30$ and $12.33 \pm 1.75$ in the two groups, respectively, with no difference between them $(\mathrm{P}>0.05)$.

The results of RT-PCR demonstrated that the VEGF mRNA level was significantly higher in the tumor-HFD group than in the tumor group $(1.24 \pm 0.69$ vs. $0.74 \pm 0.23 ; \mathrm{P}<0.05)$,

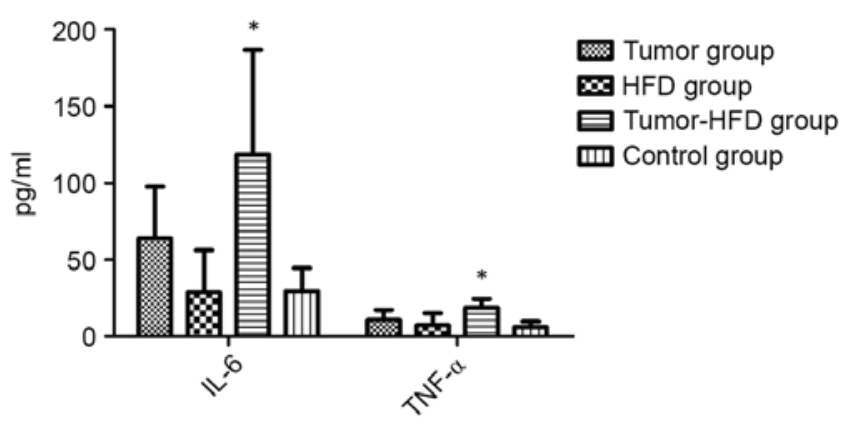

Figure 4. Serum level of IL-6 and TNF- $\alpha$. Results are expressed as the mean \pm standard deviation $(n=10)$. ${ }^{*} \mathrm{P}<0.05$ compared with the control group. IL, interleukin; TNF, tumor necrosis factor.

whereas there the ANG2 mRNA level did not differ between the groups (Fig. 5C).

Correlation analysis between IL-6, TNF- $\alpha, C D 34$ and VEGF, and metastasis. Correlation analysis results demonstrated that the frequency of metastasis was associated with the IL-6 serum level $(\mathrm{r}=0.61)$, and the expression of CD34 $(\mathrm{r}=0.941)$ and VEGF (0.679) protein in tumor tissue (all $\mathrm{P}<0.05)$. There was no evident correlation between metastasis and TNF- $\alpha(\mathrm{P}>0.05)$. 

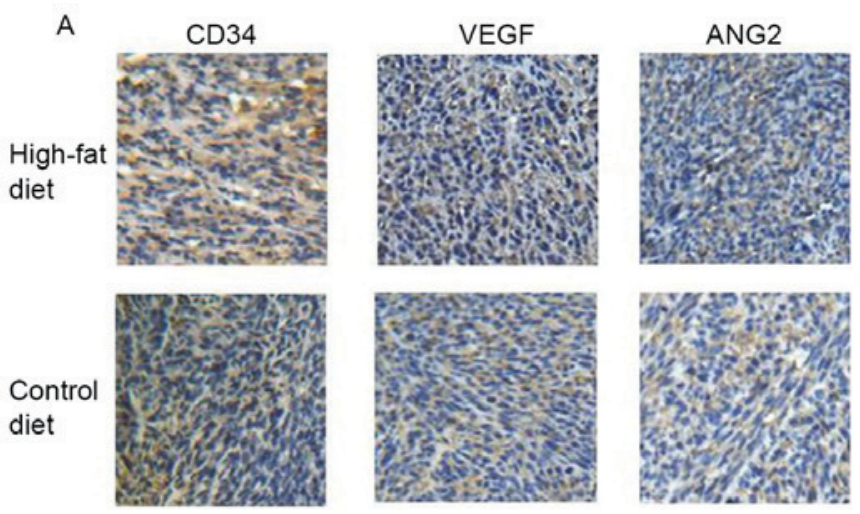

B

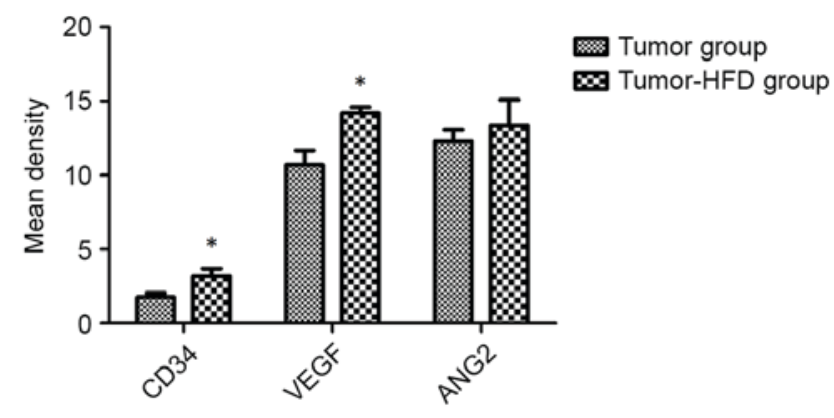

C

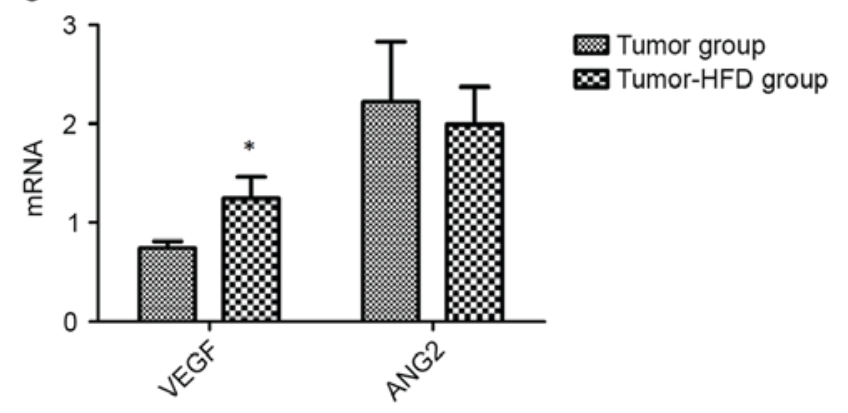

Figure 5. Levels of CD34, VEGF, and ANG2 in tumor tissue. (A) Immunohistochemistry staining of CD34, VEGF and ANG2 in tumor group and tumor-HFD group (magnification, x400). (B) Immunohistochemistry analysis of protein level, with representative results. (C) Reverse transcription polymerase chain reaction analysis of the mRNA level as determined by densitometry. Results are expressed as the mean \pm standard deviation $(n=10)$. ${ }^{*} \mathrm{P}<0.05$ compared with the tumor group rats. VEGF, vascular endothelial growth factor; ANG2, angiotensin 2; HFD, high fat diet.

\section{Discussion}

The purpose of the present study was to determine whether HFD increases colon tumor metastasis in BALB/c mice. It was observed that the metastasis frequency was more severe, with a higher level of serum cholesterol, in the tumor-HFD group compared with the tumor group. This indicated that high cholesterol induced by HFD may have served an important role in the metastasis of colon cancer. The link between dysregulated lipid levels, including high levels of cholesterol, LDL-C and TG, and colon cancer progression has previously been reported (19). Another previous study indicated that a high serum cholesterol level was associated with the distant metastasis of colon cancer (10). Cholesterol is a crucial component of cell membranes, and contributes to the organization of lipid rafts, which contain a large number of cancer-associated signaling and adhesion molecules (20). Due to the increase in the cholesterol level of tumor cells, increased lipid synthesis is also recognized as a common feature of metabolic reprogramming in cancer cells (21). Dysregulated cholesterol synthesis and sterol-dependent proliferation have been identified in various cancer cell types and may lead to cancer progression (21).

In the present study, it was observed that HFD increased the serum IL-6 and TNF- $\alpha$ levels of mice with colon cancer. Previous studies have indicated that the metabolic syndrome induced by HFD can cause inflammation (22), particularly through the oxidation of cholesterol $(23,24)$. However, HFD did not induce an inflammatory effect in normal mice, which may be due to the limited time that HFD was received. In the colon cancer model mice fed a normal diet, IL- 6 and TNF- $\alpha$ increased to a non-significant extent compared with the control mice. A correlation analysis identified that metastasis may have been associated with the serum level of IL- 6 . This indicated that the inflammation induced by HFD may contribute to colon cancer metastasis.

Clinical and epidemiological research has demonstrated an association between cancer and inflammatory metabolic diseases; common molecular characteristics between the two have been demonstrated. Hirsch et al (21) hypothesized that there was a common core signaling pathway network controlling normal cell growth and behavior. Once the core gene network is affected by genetics or the environment, a range of diseases develop, which may account for the association between cancer and metabolic disease. Regarding how a common transcriptional program contributed to this diverse range of human diseases, Hirsch et al suggested that the interplay between cell-type-specific factors and a common transcriptional program leads to cell-type-specific transcription profiles and phenotypes associated with these specific disease states. In this view, the combination of cell-type-specific factors with a common disease program can lead to inappropriate cell proliferation as associated with either cancer or metabolic diseases (21). Inflammation serves an important role in both colon cancer and metabolic diseases $(25,26)$, which may be the main mechanism for the dysregulation of cholesterol, as induced by HFD, promoting colon cancer metastasis.

In the tumor microenvironment, inflammatory factors affect tumor angiogenesis (27). In the present study, HFD increased the CD34 in tumor tissue, in addition to the serum levels of IL-6 and TNF- $\alpha$ in colon cancer model mice. IL-6 and TNF- $\alpha$ have been demonstrated to serve important roles in tumor angiogenesis $(28,29)$. VEGF is the most critical cytokine in angiogenesis; Eldesoky et al (30) reported that the serum levels of IL-6 and VEGF from 35 patients with colon cancer prior to surgery were higher than in a control group, and the patients that experienced higher cancer invasiveness and metastasis had higher IL-6 and VEGF levels. TNF- $\alpha$ derived from the tumor can promote angiogenesis by promoting the secretion of VEGF by fibroblasts (31). Likewise, tumors derived from cells with TNF- $\alpha$ knockdown exhibit a phenotype with reduced vascularization and invasiveness (32).

The increased CD34 and VEGF protein and mRNA in tumor tissue indicated that tumor angiogenesis likely increased in colon cancer model mice that received HFD. As ANG2 
protein and mRNA were not elevated in tumor tissues by HFD, VEGF induced by HFD may have promoted tumor angiogenesis. A correlation analysis demonstrated that metastasis was associated with the expression of CD34 and VEGF protein in tumor tissue. This indicated that the metastasis promotion by HFD may be associated with the induced inflammatory effect and angiogenesis. However, the specific mechanism remains to be determined through further study.

In conclusion, HFD promoted the distant metastasis of colon cancer model mice. HFD also elevated the serum level of cholesterol and the pro-inflammatory cytokines IL- 6 and TNF- $\alpha$, and potentially promoted angiogenesis in colon cancer model mice.

\section{Acknowledgments}

Not applicable.

\section{Funding}

The study was supported by SLAC and grants from the Shanghai Municipal Health Bureau of China (grant no. ZYSNXD-CC-MZY054, to PW).

\section{Availability of data and materials}

The datasets used and/or analyzed during the current study are available from the corresponding author on reasonable request.

\section{Authors' contributions}

LX performed the animal experiment and was a major contributor in writing the manuscript. ZY performed the histological examination. YZ performed the animal experiment. XL performed the serum examination and RT-PCR. JJ analyzed the data. MY performed the animal experiment. DS collected the specimens from animals. PW designed the whole examination. All authors have read and approved the manuscript.

\section{Ethics approval and consent to participate}

The study protocol was approved by the Institutional Animal Care and Use Committee of SLAC.

\section{Patient consent for publication}

Not applicable.

\section{Competing interests}

The authors declare that they have no competing interests.

\section{References}

1. Siegel R, Naishadham D and Jemal A: Cancer statistics, 2013. CA Cancer J Clin 63: 11-30, 2013.

2. Yao Z, Zhang L and Ji G: Efficacy of polyphenolic ingredients of Chinese herbs in treating dyslipidemia of metabolic syndromes. J Integr Med 12: 135-146, 2014.

3. Feng X, Scott A, Wang Y, Wang L, Zhao Y, Doerner S, Satake M Croniger CM and Wang Z: PTPRT regulates high-fat diet-induced obesity and insulin resistance. PLoS One 9: e100783, 2014.
4. Song HY, Zhang L, Pan JL, Yang LL and Ji G: Bioactivity of five components of Chinese herbal formula Jiangzhi granules against hepatocellular steatosis. J Integr Med 11: 262-268, 2013.

5. Wu J, Zhang $\mathrm{H}$, Zheng $\mathrm{H}$ and Jiang Y: Hepatic inflammation scores correlate with common carotid intima-media thickness in rats with NAFLD induced by a high-fat diet. BMC Vet Res 10 : 162,2014

6. Khanna AK: Enhanced susceptibility of cyclin kinase inhibitor p21 knockout mice to high fat diet induced atherosclerosis. J Biomed Sci 16: 66, 2009.

7. Potter JD: Nutrition and colorectal cancer. Cancer Causes Control 7: 127-146, 1996.

8. Yiu HY, Whittemore AS and Shibata A: Increasing colorectal cancer incidence rates in Japan. Int J Cancer 109: 777-781, 2004.

9. Liu CS, Hsu HS, Li CI, Jan CI, Li TC, Lin WY, Lin T, Chen YC, Lee CC and Lin CC: Central obesity and atherogenic dyslipidemia in metabolic syndrome are associated with increased risk for colorectal adenoma in a Chinese population. BMC Gastroenterol 10: 51, 2010.

10. Notarnicola M, Altomare DF, Correale M, Ruggieri E, D'Attoma B, Mastrosimini A, Guerra V and Caruso MG: Serum lipid profile in colorectal cancer patients with and without synchronous distant metastases. Oncology 68: 371-374, 2005.

11. He T, Qi F, Jia L, Wang S, Song N, Guo L, Fu Y and Luo Y: MicroRNA-542-3p inhibits tumour angiogenesis by targeting angiopoietin-2. J Pathol 232: 499-508, 2014.

12. Hosseini H, Rajabibazl M, Ebrahimizadeh W and Dehbidi GR: Inhibiting angiogenesis with human single-chain variable fragment antibody targeting VEGF. Microvasc Res 97: 13-18, 2015.

13. Huang Y, Song N, Ding Y, Yuan S, Li X, Cai H, Shi H and Luo Y: Pulmonary vascular destabilization in the premetastatic phase facilitates lung metastasis. Cancer Res 69: 7529-7537, 2009.

14. Huang H, Bhat A, Woodnutt G and Lappe R: Targeting the ANGPT-TIE2 pathway in malignancy. Nat Rev Cancer 10: 575-585, 2010.

15. Augustin HG, Koh GY, Thurston G and Alitalo K: Control of vascular morphogenesis and homeostasis through the angiopoietin-Tie system. Nat Rev Mol Cell Biol 10: 165-177, 2009.

16. Carvalho MI, Pires I, Prada J, Raposo TP, Gregório H, Lobo L and Queiroga FL: High COX-2 expression is associated with increased angiogenesis, proliferation and tumoural inflammatory infiltrate in canine malignant mammary tumours: A multivariate survival study. Vet Comp Oncol 15: 619-631, 2017.

17. Jakobsdottir G, Xu J, Molin G, Ahrné S and Nyman M: High-fat diet reduces the formation of butyrate, but increases succinate, inflammation, liver fat and cholesterol in rats, while dietary fibre counteracts these effects. PLoS One 8: e80476, 2013.

18. Perry B, Zhang J, Saleh T and Wang Y: Liuwei Dihuang, a traditional Chinese herbal formula, suppresses chronic inflammation and oxidative stress in obese rats. J Integr Med 12: 447-454, 2014

19. Zhang X, Zhao XW, Liu DB, Han CZ, Du LL, Jing JX and Wang Y: Lipid levels in serum and cancerous tissues of colorectal cancer patients. World J Gastroenterol 20: 8646-8652, 2014.

20. Murai T: Cholesterol lowering: Role in cancer prevention and treatment. Biol Chem 396: 1-11, 2015.

21. Hirsch HA, Iliopoulos D, Joshi A, Zhang Y, Jaeger SA, Bulyk M, Tsichlis PN, Shirley Liu X and Struhl K: A transcriptional signature and common gene networks link cancer with lipid metabolism and diverse human diseases. Cancer Cell 17: 348-361, 2010.

22. Cano Barquilla P, Pagano ES, Jiménez-Ortega V, Fernández-Mateos P, Esquifino AI and Cardinali DP: Melatonin normalizes clinical and biochemical parameters of mild inflammation in diet-induced metabolic syndrome in rats. J Pineal Res 57: 280-290, 2014.

23. Jusakul A, Yongvanit P, Loilome W, Namwat N and Kuver R: Mechanisms of oxysterol-induced carcinogenesis. Lipids Health Dis 10: 44, 2011.

24. Kampschulte M,StöcklC,Langheinrich AC,Althöhn U,BohleRM, Krombach GA, Stieger P, Churin Y, Kremer S, Dierkes C, et al: Western diet in ApoE-LDLR double-deficient mouse model of atherosclerosis leads to hepatic steatosis, fibrosis, and tumorigenesis. Lab Invest 94: 1273-1282, 2014.

25. Flores MBS, Rocha GZ, Damas-Souza DM, Osório-Costa F, Dias MM, Ropelle ER, Camargo JA, de Carvalho RB, Carvalho HF, Saad MJA and Carvalheira JBC: RETRACTED: Obesity-induced increase in tumor necrosis factor- $\alpha$ leads to development of colon cancer in mice. Gastroenterology 143: 741-753.e4, 2012. 
26. Al Rifai M, Silverman MG, Nasir K, Budoff MJ, Blankstein R, Szklo M, Katz R, Blumenthal RS and Blaha MJ: The association of nonalcoholic fatty liver disease, obesity, and metabolic syndrome, with systemic inflammation and subclinical atherosclerosis: The multi-ethnic study of atherosclerosis (MESA). Atherosclerosis 239: 629-633, 2015.

27. Landskron G, De la Fuente M, Thuwajit $P$, Thuwajit $C$ and Hermoso MA: Chronic inflammation and cytokines in the tumor microenvironment. J Immunol Res 2014: 149185, 2014.

28. Hefler LA, Grimm C, Ackermann S, Malur S, Radjabi-Rahat AR, Leodolter S, Beckmann MW, Zeillinger R, Koelbl H and Tempfer CB: An interleukin-6 gene promoter polymorphism influences the biological phenotype of ovarian cancer. Cancer Res 63: 3066-3068, 2003.

29. Middleton K, Jones J, Lwin Z and Coward JI: Interleukin-6: An angiogenic target in solid tumours. Crit Rev Oncol Hematol 89: 129-139, 2014.
30. Eldesoky A, Shouma A, Mosaad Y and Elhawary A: Clinical relevance of serum vascular endothelial growth factor and interleukin-6 in patients with colorectal cancer. Saudi J Gastroenterol 17: 170-173, 2011.

31. Danese S, Sans M, de la Motte C, Graziani C, West G, Phillips MH, Pola R, Rutella S, Willis J, Gasbarrini A and Fiocchi C: Angiogenesis as a novel component of inflammatory bowel disease pathogenesis. Gastroenterology 130: 2060-2073, 2006.

32. Kulbe H, Thompson R, Wilson JL, Robinson S, Hagemann T, Fatah R, Gould D, Ayhan A and Balkwill F: The inflammatory cytokine tumor necrosis factor-alpha generates an autocrine tumor-promoting network in epithelial ovarian cancer cells. Cancer Res 67: 585-592, 2007. 